ÖGUM-Mitteilungen

Österreichische Gesellschaft für Ultraschall

in der Medizin

\title{
ÖGUM
}

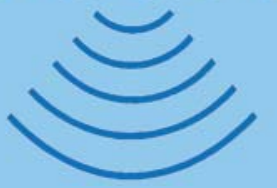

\section{Neue Kursleiter}

Bei der letzten Vorstandssitzung am 13.01.2017 in Linz wurden folgende Personen zu ÖGUM-Kursleitern ernannt:

Für die Notfallsonografie: OA Dr. Gustav Huber (Donauspital, 1. Med. Abteilung, Langobardenstraße 122, 1220 Wien) und
Dr. Peter Michael Zechner (LKH Graz SüdWest, Abteilung für Innere Medizin

Göstingerstrasse 22, $8020 \mathrm{Graz}$ ), sowie für die Nervensonografie: Priv.-Doz. Dr. Stefan Meng
(KFJ Spital, SMZ-Süd, Zentralröntgeninstitut, Kundratstraße 3, 1100 Wien).

Der Vorstand wünscht allen neuen Kursleitern viel Zuspruch bei Ihren neuen Kursangeboten! 